\section{References}

1. Turley K, Szarnicki RJ, Flachsbart KD, Richter RC, Popper RW, Tarnoff H. Aortic implantation is possible in all cases of anomalous origin of the left coronary artery from the pulmonary artery. Ann Thorac Surg. 1995;60:84-9.
2. Atik E, Barbero-Marcial M, Tanamati C, Kajita L, Ebaid M, Jatene A. Anomalous origin of the left coronary artery from the right pulmonary artery with intramural aortic trajectory: clinicosurgical diagnostic implications [translated from Portguese]. Arq Bras Cardiol. 1999;73: 186-90.

\title{
Retrograde aortic perfusion dislodges a dislodged Amplatzer device
}

\author{
Zubair Luqman, FCPS, Junaid A. Ansari, FRCS(CTh), Hameed Ullah, FCPS, and Mohammad Muneer Amanullah, FRCS(CTh), \\ Karachi, Pakistan
}

$\mathrm{T}$

ranscatheter closure of secundum atrial septal defects (ASDs) with an Amplatzer septal occluder (ASO) (AGA Medical Corporation, Golden Valley, Minn) has become a standard procedure in most pediatric and adult populations. ${ }^{1}$ Different series have reported successful closure of ASDs with good follow-up..$^{1-3}$ One of the most frequently reported complications is device embolization/malposition. ${ }^{1}$ Devices usually embolize into the main pulmonary artery. We report a case of device embolization into the aorta and the strategy for surgical retrieval.

\section{Clinical Summary}

A 53-year-old woman presented to the cardiology clinic with complaints of palpitations. Echocardiographic analysis revealed a 15$\mathrm{mm}$ secundum ASD. She underwent elective closure of the ASD with ASO without any complications. Her predischarge echocardiogram revealed that the ASD was still present. Fluoroscopic study of the thorax showed that the device had embolized into the ascending aorta (Figure 1). She was taken to the operating room for retrieval of the device and closure of the ASD. A transesophageal echocardiogram (TEE) was performed after induction, which confirmed the presence of the device in the ascending aorta just proximal to the innominate artery. The initial plan was to start the patient on circulatory arrest and retrieve the device. Femoral bypass was initiated, and hypothermia was used. Adequate exposure of the ascending aorta was obtained, avoiding manipulation of the aorta, with plans of aortotomy and ASO retrieval during circulatory arrest.

On initiation of femoral bypass, it was observed on TEE that the device could no longer be visualized in the ascending aorta. A fluoroscopic scan using a C-arm was performed, and it demonstrated

From the Division of Congenital Cardiac Surgery, Department of Surgery, the Aga Khan University Hospital, Karachi, Pakistan.

Received for publication Sept 28, 2007; accepted for publication Oct 31, 2007.

Address for reprints: Mohammad Muneer Amanullah, FRCS(CTh), Congenital Cardiac Surgery, the Aga Khan University Hospital, Stadium Road, PO Box 3500, Karachi 74800, Pakistan (E-mail: muneer.amanullah@aku.edu).

J Thorac Cardiovasc Surg 2008;135:698-9

$0022-5223 / \$ 34.00$

Copyright $\odot 2008$ by The American Association for Thoracic Surgery doi:10.1016/j.jtcvs.2007.10.050

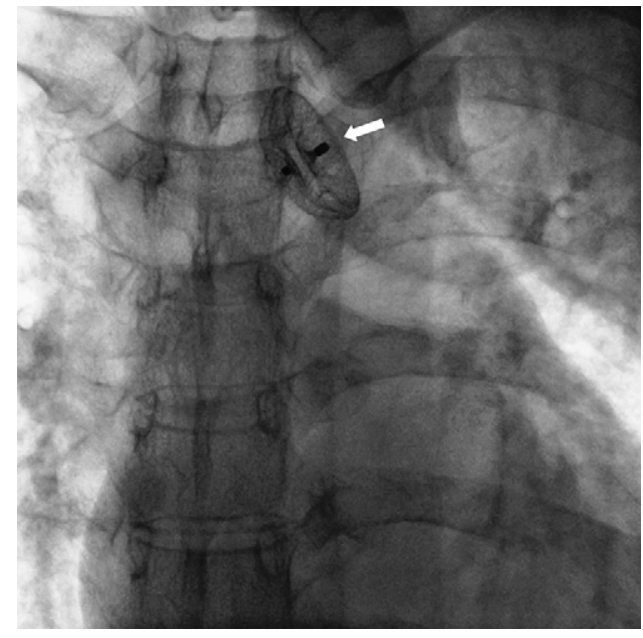

Figure 1. Photograph showing the dislodged amplatzer device in the ascending aorta (white arrow).

that the device had embolized back into the left ventricle. An aortic crossclamp was applied, and antegrade cold blood cardioplegia was administered. A right atriotomy was performed, and the device was visualized through the ASD to be lying in the left ventricle, entangled in the chordae of the mitral valve. The device was retrieved through the ASD. Direct closure of the ASD was performed with Prolene sutures (Ethicon, Inc, Somerville, NJ). The right atriotomy incision was closed. Postoperative echocardiographic analysis did not reveal any residual defect or mitral or aortic valve insufficiency. The patient made a smooth postoperative recovery and was discharged in a week.

\section{Discussion}

ASOs have been used successfully in the adult population, with a low failure rate. ${ }^{1}$ Device embolization or malposition is the most frequently reported complication, and in one series it was $3.5 \%{ }^{2}$

It is reported that there is an age-related decrease in the rate of complications for device closure of ASD, with studies involving children having the lowest complication rates. ${ }^{4}$ Embolization of a device in an adult has rarely been reported. 
We did not attempt to retrieve the device percutaneously because of the fear of more distal embolization. The patient was taken to the operating room soon after the diagnosis was made. An interesting situation arose when the device could not be found in the ascending aorta, where it was initially reported to be present. We think that initiation of femoral bypass resulted in the device being pushed back into the proximal aorta. With subsequent aortic crossclamping and antegrade cold blood cardioplegia, it slipped through the aortic valve into the left ventricle and got entangled in the submitral apparatus.

The decision to start the patient on deep hypothermia with plans of circulatory arrest was made for fear of distal embolization during aortic manipulation. It seems that the femoral artery bypass pressure helped by pushing the device back near the aortic valve and, with subsequent antegrade cardioplegia, pushed the device through the aortic valve into the left ventricle and then toward the left atrium, and this saved the patient from an aortic intervention. This phenomenon has not been described in the literature to the best of our knowledge.
We propose that when an ASO has embolized to the aorta, femoral cannulation and cardiopulmonary bypass, along with transesophageal echocardiography and fluoroscopy to localize the device accurately, should be used.

\section{References}

1. Spies C, Timmermanns I, Schrader R. Transcatheter closure of secundum atrial septal defects in adults with the Amplatzer septal occluder: intermediate and long-term results. Clin Res Cardiol. 2007;96:340-6.

2. Chessa M, Carminati M, Butera G, Bini RM, Drago M, Rosti L, et al. Early and late complications associated with transcatheter occlusion of secundum atrial septal defect. J Am Coll Cardiol. 2002;39:1061-5.

3. Fischer G, Stieh J, Uebing A, Hoffmann U, Morf G, Kramer HH. Experience with transcatheter closure of secundum atrial septal defects using the Amplatzer septal occluder: a single centre study in 236 consecutive patients. Heart. 2003;89:199-204.

4. Du ZD, Hijazi ZM, Kleinman CS, Silverman NH, Larntz K. Amplatzer Investigators. Comparison between transcatheter and surgical closure of secundum atrial septal defect in children and adults: results of a multicenter nonrandomized trial. J Am Coll Cardiol. 2002;39:1836-44.

\title{
Thoracic endovascular aortic repair of adult patent ductus arteriosus with pulmonary hypertension
}

\author{
Yong-Qiang Lai, MD, ${ }^{a}$ Shang-Dong Xu, MD, ${ }^{a}$ Zhi-Zhong Li, MD, ${ }^{\mathrm{b}}$ Bao-Zhong Yang, MD, ${ }^{\mathrm{c}}$ Su Wang, MD, ${ }^{\mathrm{b}}$ Jin-Hua Li, MD, \\ Jing-Wei Li, MD, ${ }^{a}$ Yi Luo, MD, ${ }^{a}$ and Zhao-Guang Zhang, MD, ${ }^{a}$ Beijing, China
}

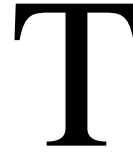

horacic endovascular aortic repair (TEVAR) has emerged as an alternative treatment for adult patent ductus arteriosus (PDA) in recent years. ${ }^{1}$ We report here our preliminary experience in treating adult PDA with stent-grafts.

\section{Clinical Summary}

From September 2005 to March 2007, a total of 4 patients with a large PDA and pulmonary hypertension underwent TEVAR. All patients had exertional dyspnea. Transthoracic echocardiography, computed tomographic angiography, and right heart catheterization were conducted before the operation. All patients had severe pulmonary hypertension. Indications for stent-graft implantation were as follows: (1) adult patient with large PDA, (2) no other congenital

From the Divisions of Cardiac Surgery, ${ }^{\mathrm{a}}$ Cardiology, ${ }^{\mathrm{b}}$ and Vascular Surgery, ${ }^{\mathrm{C}}$ Beijing Anzhen Hospital, Beijing Institute of Heart, Lung, \& Vascular Diseases, Capital Medical University, Beijing, China.

Received for publication Sept 3, 2007; accepted for publication Nov 26, 2007.

Address for reprints: Yong-Qiang Lai, MD, Division of Cardiac Surgery, Beijing Anzhen Hospital, 36 Wuluju Chaoyang District, Beijing, China, 100029 (E-mail: yongqianglai@yahoo.com).

J Thorac Cardiovasc Surg 2008;135:699-701

0022-5223/ $\$ 34.00$

Copyright $@ 2008$ by The American Association for Thoracic Surgery doi:10.1016/j.jtcvs.2007.11.028

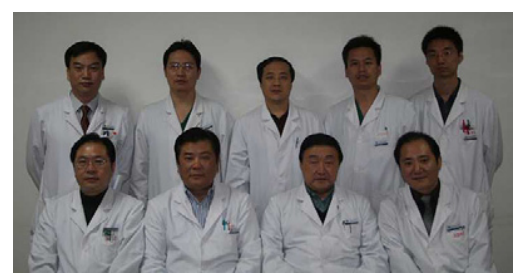

Drs $\mathrm{Xu}, \mathrm{J}-\mathrm{W} \mathrm{Li}, \mathrm{Z}-\mathrm{Z} \mathrm{Li}, \mathrm{J}-\mathrm{H} \mathrm{Li}$, and Wang (top row, left to right); Drs Yang, Luo, Zhang, and Lai (bottom row, left to right).

cardiac defects, (3) no right-to-left shunt, (4) adequate landing zone (arch diameter $<35 \mathrm{~mm}$ ), and (5) adequate access route. The study was approved by the institutional review board, and informed consent was obtained. Clinical data are summarized in Table 1.

TEVAR was performed in a catheter laboratory with general anesthesia. The TEVAR procedure is described in detail in our previous article. ${ }^{4}$ Brachial and pulmonary arterial pressures were monitored. Different arteries were used as access routes. The right common femoral artery was used in 2 patients. Transperitoneal exposure of the abdominal aorta was performed in 1 patient. The common iliac artery was mobilized through the postperitoneal approach by a left oblique hypogastric incision in 1 patient. Tapered stentgrafts (Grikin Advanced Materials Co, Ltd, Beijing, China) were used. The left subclavian artery (LSCA) was covered simultaneously in all patients.

Stent-grafts were successfully implanted in all patients. Mean pulmonary arterial pressure decreased from $65.8 \pm 8.4 \mathrm{~mm} \mathrm{Hg}$ 